\title{
Inverted E-Shape Micro Strip Patch for Dual Band
}

\author{
Survase Kashiram \\ S. S. I. E. M. Parbhani
}

\author{
Patange Amol \\ S. S. I. E. M. Parbhani
}

\begin{abstract}
The objective of this paper is to design, and fabricate an inset fed rectangular microstrip patch antenna. In this paper we tested our design by using the electromagnetic solver, simulator (IE3D), was used to numerically investigate and optimize the proposed antenna configuration. Besides the structure external dimensions, the influence of the various antenna parameters on the resonant behavior have been observed. It has been found that the symmetrical position of patch over ground plane have clear impact on overall antenna performance. Many antenna structures have been modeled to demonstrate the effects of these parameters on the resulting dual band response. We design antenna for lower band (2.64$2.85 \mathrm{GHz})$ and upper band (7.03-7.21GHz).
\end{abstract}

\section{Keywords}

Micro strip antenna; IE3D SIMULATOR; Dielectric; Patch width; Patch Length; Losses; strip width; strip length.

\section{INTRODUCTION}

Various E-shaped patch antennas with tapered, corrugated, and trapezoidal slots have been reported in the literature. Ahmed H. Reja [1] proposed Study of Micro Strip Feed Line Patch Antenna experimentally increase the Return Loss $33.60 \mathrm{~dB}$ at $2.5 \mathrm{GHz}$ frequency and VSWR is $1.5 \mathrm{RT}$ DUROID 5880. Santanu Kumar Behera and Y. Choukiker [2] proposed Design and Optimization of Dual Band Micro Strip Antenna using Practical Swarm Optimization maximize the return loss for dual band Frequency at $2.4 \mathrm{GHz}$ is $43.9 \mathrm{~dB}$ and at $3.08 \mathrm{GHz}$ is $-27.4 \mathrm{~dB}$. A A Deshmukh and $\mathrm{G}$ Kumar [3] proposed compact L-Shape patch broadband Microstrip antenna experimentally increase bandwidth up to 13.7\%. Z M Chen [4] further increase bandwidth of this antenna up to $23.7 \%$ - $24.43 \%$. K F Lee [5] proposed UShape slot shorting post small size Microstrip Antenna and increase bandwidth up to $42 \%$. S C Gao [6] used uniplanar photonic band gap structure for enhancing band width and gain. M Khodier [7] New wideband stacked microstrip antennas for enhancing band width. Major issue for micro strip antenna is narrow Bandwidth. . Jawed K. Ali [8] proposed E-shaped microsrtip antenna for UWB application with return loss $-40 \mathrm{~dB}$. A. K. Arya [9] demonstrated for dual band F-shaped antennathat is for $3.15 \mathrm{GHz}$ and 4.47 $\mathrm{GHz}$, experimentally increases return loss $-29 \mathrm{~dB}$ and $-45 \mathrm{~dB}$ for each band respectively New wideband stacked microstrip antennas for enhancing band width. Major issue for micro strip antenna is narrow Bandwidth.

In this paper we tested our design by using electromagnetic simulator (IE3D). IE3D is an integral equation, method of moment, full-wave electromagnetic simulator. It includes layout editor, electromagnetic simulator, schematic editor and circuit simulator, near field calculation program, format converter, current and field display program. IE3D employs a 3D non-uniform triangular and rectangular mixed meshing scheme. It solves the current distribution, slot-field distribution, network parameters, and radiation patterns, near field on an arbitrarily shaped and oriented 3D metallic structure in a multi-layered dielectric environment.

\section{PROPOSED DESIGNED}

The results of proposed dual band microstrip patch antenna verified in IE3D Simulator with optimization. The initial antenna is shown in Figure 1. It consists of a 2-slot at each end and placed within the patch [7]. The resulting antenna structure has the following parameters; the patch shape length $\mathrm{Lp}=28.3 \mathrm{~mm}$, and its width $\mathrm{Wp}=24.3 \mathrm{~mm}$. The size of the ground plane has been found to be of $\mathrm{Lg}=30 \mathrm{~mm}$ and $\mathrm{Wg}=$ $30 \mathrm{~mm}$. The dielectric material selected for the design is an FR4 with glass epoxy substrate of height $\mathrm{h}=1.57 \mathrm{~mm}$ and $\mathrm{\varepsilon r}=$ 4.34. A $50 \Omega$ inset microstripline feed is attached to the microstrip and has a width $\mathrm{Wt}=2.70 \mathrm{~mm}$ and length $\mathrm{Lt}=$ $40.2 \mathrm{~mm}$ The inset length y0 is chosen such that impedance matching is achieved [8]. The length of the inset feed is $\mathrm{y} 0=$ $12.15 \mathrm{~mm}$.

We will conduct a simulation study on the structure of Figure 1 by adjusting the patch position on ground plane, initially we put patch on left side of ground plane i. e. patch unsymmetrical. As we increase the patch length on ground from left side matching is increased tremendously, presented in table 1 and table 2 for first and second band respectively.

Table 1. Changing shape of patch on ground (First band)

\begin{tabular}{|c|c|c|}
\hline $\begin{array}{c}\text { Patch adjustment } \\
\text { on ground from } \\
\text { Left of patch } \\
\text { (mm) }\end{array}$ & $\begin{array}{c}\text { Resonant } \\
\text { frequency (GHz) }\end{array}$ & $\begin{array}{c}\text { Return Loss } \\
\text { (S11 in dBm) }\end{array}$ \\
\hline $\begin{array}{c}\text { Patch on extreme } \\
\text { left ground plane }\end{array}$ & 2.57 & -18.05 \\
\hline 0.2 & 2.6 & -20.1 \\
\hline 0.4 & 2.64 & -24.03 \\
\hline 0.8 & 2.67 & -22.5 \\
\hline 1.0 & & -19.07 \\
\hline 1.2 & 2.68 & \\
\hline & & \\
\hline
\end{tabular}




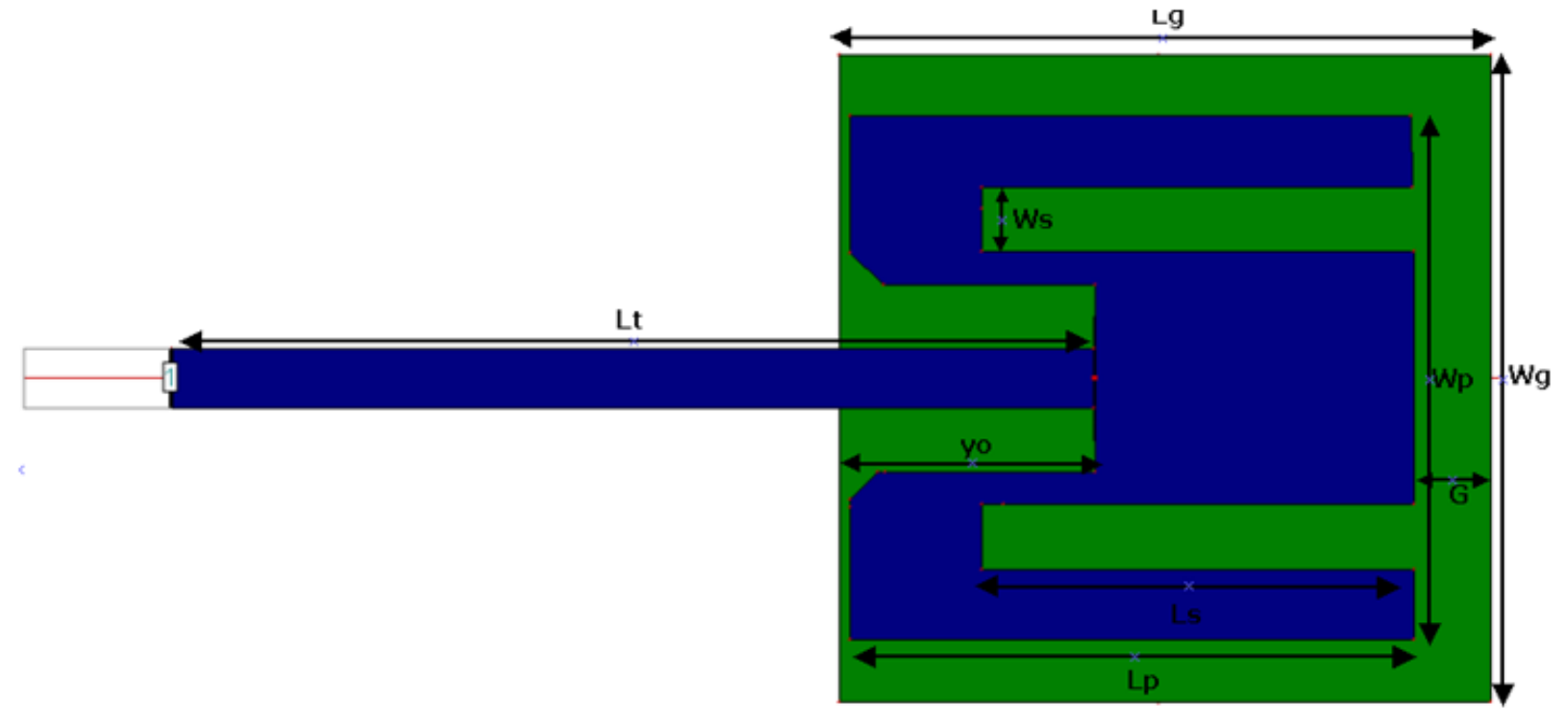

Figure 1. Proposed antenna design

Table 2. Changing shape of patch on ground (Second band)

\begin{tabular}{|c|c|c|}
\hline $\begin{array}{c}\text { Patch adjustment } \\
\text { on ground from } \\
\text { Left of patch } \\
\text { (mm) }\end{array}$ & $\begin{array}{c}\text { Resonant } \\
\text { frequency(GHz) }\end{array}$ & $\begin{array}{c}\text { Return Loss (S11 } \\
\text { in dBm) }\end{array}$ \\
\hline $\begin{array}{c}\text { Patch on extreme } \\
\text { left ground plane }\end{array}$ & 7.00 & -12.5 \\
\hline 0.2 & 7.1 & -13.1 \\
\hline 0.4 & 7.12 & -16.04 \\
\hline 0.8 & 7.16 & -22.1 \\
\hline 1.0 & 7.17 & -20.2 \\
\hline 1.2 & 7.21 & -17.4 \\
\hline
\end{tabular}

Figure 2 depicts the resulting return loss responses before moving patch on ground that is patch on extreme left of ground plane.

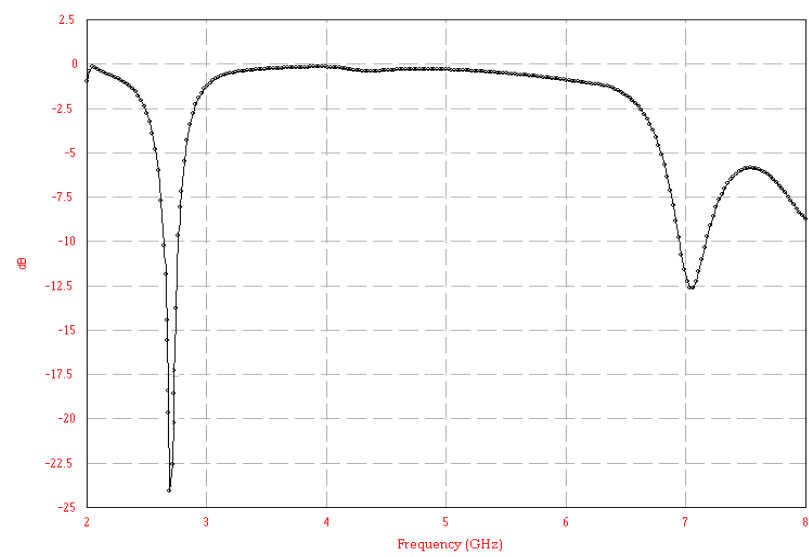

Fig 2: Return loss without patch variation on ground plane (extreme left)
From Figure 2, it observed that we get first band with sufficient return loss. Figure 3 depicts the resulting return loss responses obtained by moving patch from left to right on ground plane presented in table 1 and table 2 . Also current distribution for first and second band is presented in figure 3 and figure 4 respectively.

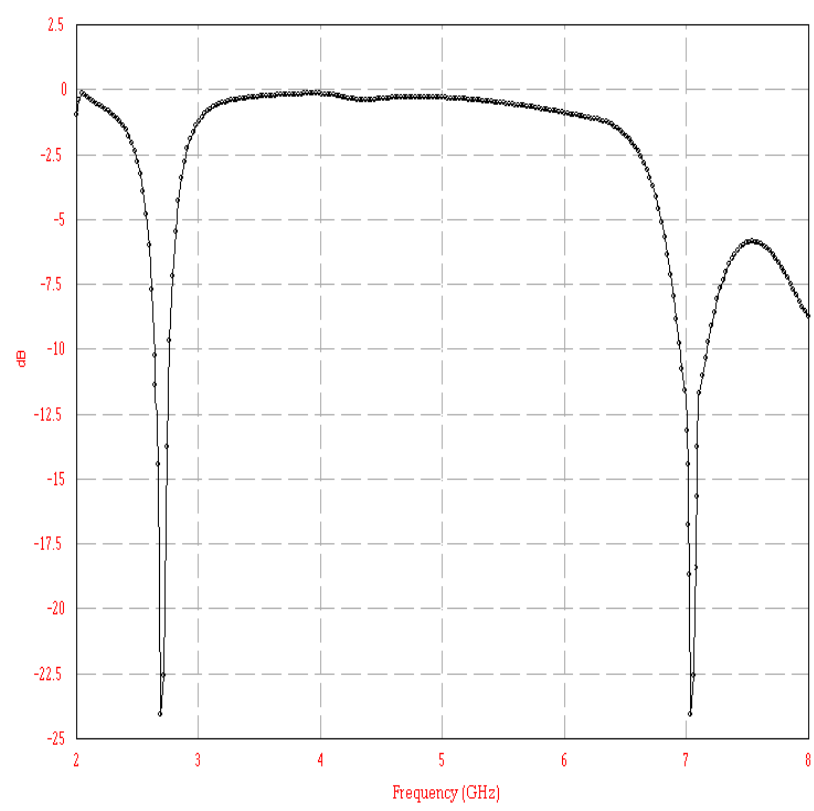

Fig 3: Return loss for with patch variation on ground

Figure 4 depicts the resulting current distribution for first band that is we present current distribution at $2.64 \mathrm{GHz}$ frequency since return loss at this frequency is -22.5 . Also figure 5 depicts the resultin current distribution for second band that is at $7.16 \mathrm{GHz}$ since return loss at this frequency is 22.1 . 


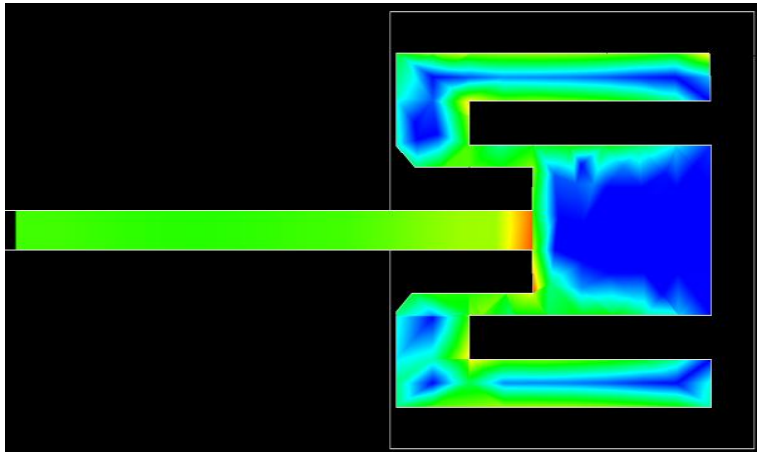

Figure 4. Current distribution for first band

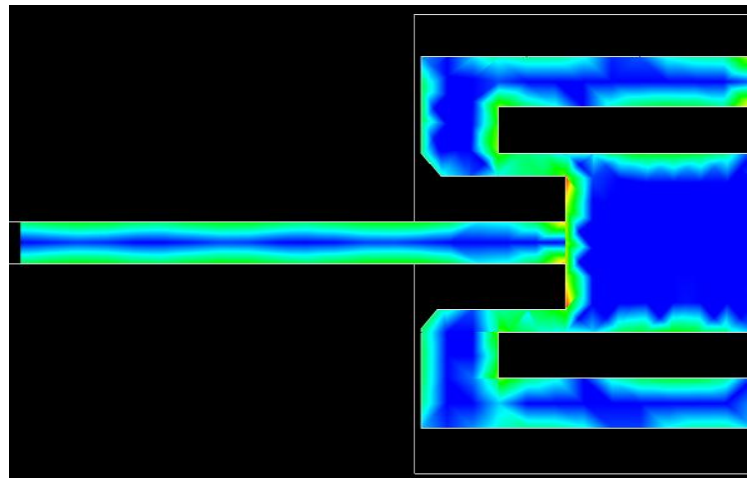

Figure 5. Current distribution for second band

\section{CONCLUSION}

An inverted E-shaped printed dual band antenna is presented in this paper, as a candidate for use for two band that is (2.64$2.85 \mathrm{GHz})$ and $(7.03-7.21 \mathrm{GHz})$. The antenna has been modeled and its performance has been analyzed using a method of moment based software, IE3D. The proposed antenna has been found to possess a miniaturized size and a and width making it suitable for compact size dual band applications.

\section{REFERENCES}

[1] Ahmed H. Reja "Study of Micro Strip Feed Line Patch Antenna", Antennas and Propagation International Symposium, vol. 27, pp. 340-342 December 2008.

[2] Sahntanu Kumar Behera and Y. Choukiker, "Design and Optimization of Dual Band Micro Strip Antenna
Using Practicle Swarm Optimization Technique," in Springer Science+Business Media, LLC, pp. 1346-1354, 2010.

[3] A. A. Deshmukh and G. Kumar, "Compact broadband gap-coupled shorted L-shaped microstrip antennas," in IEEE Antennas and Propagation International Symposium, vol 1, (Baltimore, Maryland), pp. 106109, IEEE, July 2001.

[4] Z. M.Chen and Y.W.M. Chial, "Broadband probe-fed L-shaped plate antenna," Microwave and Optical Technology Letters, vol. 26, pp. 204-206, 1985.

[5] K. F. Lee, K. M. Luk, K. F. Tong, Y. L. Yung, and T. Huynh, "Experimental study of the rectangular patch with a U-shaped slot," in IEEE Antennas and Propagation International Symposium, vol. 1, (Baltimore, Maryland), pp. 10-13, IEEE, July 1996.

[6] S. C. Gao, L. W. Li, M. S. Leong, and T. S. Yeo, "Design and analysis of a novel wideband microstrip antenna," in IEEE Antennas and Propagation International symposium,vol. 1, (Boston, Massachusetts), pp. 90-93, IEEE, July 2001.

[7] M. Khodier and C. Christodoulou, "A technique to further increase the bandwidth Of stacked microstrip antennas," in IEEE Antennas and Propagation International Symposium, vol. 3, (Salt Lake City, Utah), pp. 1394-1397, IEEE, July 2000.

[8] Jawad K. Ali and Ahmad S. Hussain, "A New Miniaturized E-shaped Printed Monopole Antenna for UWB Applications" Progress In Electromagnetics Research Symposium Proceedings, Suzhou, China, Sept. $12-16,2011$

[9] A. K. Arya, A. Patnaik, and M. V. Kartikeyan, "microstrip patch antenna with skew-F shaped DGS for dual band operation", Progress In Electromagnetics Research M, Vol. 19, 147-160, 2011

[10] K. -L. Wong and W. -H. Hsu, "A Broad-Band Rectangular PatchAntenna with a Pair of Wide Slits," IEEE Trans. Antennas Propagation, vol. 49, no.9, pp. 1345-1347, Sept.2001 